OP2 CARE QUALITY COMMISSION COMPLIANCE AND FREQUENTLY ASKED QUESTIONS

Tracy Ruthven, ${ }^{1}$ Maddie Blackburn, ${ }^{2}$ Jonathan Ellis ${ }^{3}$ Clinical Audit Support Centre, Leicester, UK; ${ }^{2}$ Children's Hospices UK, Bristol, UK; ${ }^{3}$ Help the Hospices, London, UK

10.1136/bmjspcare-2011-000100.2

As part of the Department of Health initiative - $£ 30$ million funding for children's palliative care in 2010/11, Children's Hospices UK successfully submitted a proposal with Help the Hospices relating to Care Quality Commission (COC) registration and compliance with the statutory Essential Standards of Quality and Safety.

The project ran between December 2010 and March 2011 developing guidance and best practice examples for hospice services in England.

The project assisted children's and adult hospice services by providing information to:

- Inform future development and planning of services to ensure best practice

- Identify current services and gaps in current compliance

- Work with our partner 'Help the Hospices' to share project outputs and support the transition agenda between children's and adult services.

The project required a mixed methodology to ensure effective delivery of the project objectives. Methodologies employed included an online questionnaire, stakeholder visits and interviews, delivery of three educational workshops, academic review of compliance techniques and partnership working with stakeholders to complete exemplar compliance assessments.

The project enabled a number of outputs and analysis and these were shared with member organisations via the extranet services of both Children's Hospices UK and Help the Hospices.

\title{
Outputs included:
}

- Establishment of information relating to registered activities across hospice services

- Provision of educational workshops led by the COC in relation to compliance, inspection and the Judgement Framework

- The development of a 'Compliance Toolkit' providing information and advice relating to meeting the Essential Standards including exemplar compliance assessments

- Partnership with 'Help the Hospices' to further improve transition for life limited young people by understanding the population of children and young people with palliative care needs who will be moving to adult services.

The presentation will focus on some of the learning from this joint venture and consider next steps. 